\title{
Human hair follicle and interfollicular keratinocyte reactivity to mouse HPV16-transformed cells: An in vitro study
}

\author{
KAREL SMETANA Jr ${ }^{1,2}$, BARBORA DVORÁNKOVÁ ${ }^{1,2}$, LUKÁS LACINA ${ }^{1,2,3}$, \\ ZDENEK CADA $^{1,2,4}$ and VLADIMÍR VONKA ${ }^{5}$ \\ ${ }^{1}$ Charles University in Prague, First Faculty of Medicine, Institute of Anatomy; ${ }^{2}$ Charles University in \\ Prague, Second Faculty of Medicine, Center of Cell Therapy and Tissue Repair; ${ }^{3}$ Charles University in \\ Prague, First Faculty of Medicine, Department of Dermatovenereology; ${ }^{4}$ Charles University in \\ Prague, First Faculty of Medicine, Department of Otorhinolaryngology and Head and Neck \\ Surgery; ${ }^{5}$ Institute of Hematology and Blood Transfusion, Prague, Czech Republic
}

Received March 18, 2008; Accepted April 30, 2008

\begin{abstract}
The role of stem cells in cancer formation and spreading has been established. As with normal tissue, the cancer stem cells need a special microenvironment to support their growth. This microenvironment may be represented by the tumor stroma. One of the possible ways of tumor stromal formation is the epithelial-mesenchymal transition of tumor epithelium. Following this mechanism, stromal cells must share the basic genetic alterations with the tumor cells. In an attempt to create a system capable of testing some aspects of the mesenchymal cell-keratinocyte interactions, we studied the effects of the fibroblastoid mouse TC- 1 cells that were prepared by the introduction of human papillomavirus type 16 (HPV16) genes E6 and E7 to lung epithelial cells on the phenotype of normal human interfollicular and hair follicle keratinocytes. From this point of view, they may resemble stromal cells formed by the epithelial-mesenchymal transition of cells from HPV-induced squamous cell carcinoma. In contrast to $3 \mathrm{~T} 3$ murine embryonic fibroblasts which were used as control cells, TC-1 cells influenced not only the size of the keratinocytes and the shape of their colonies, but also induced the expression of keratins 8 and 19 and vimentin. In conclusion, TC- 1 cells exhibited a marked biological activity by influencing the behavior of the normal human follicular and intefollicular keratinocytes. This observation is compatible with the hypothesis that stromal cells play an important role in tumor progression and spreading.
\end{abstract}

Correspondence to: Professor Karel Smetana Jr, Charles University, First Faculty of Medicine, Institute of Anatomy, U nemocnice 3, 12800 Prague 2, Czech Republic

E-mail: karel.smetana@lf1.cuni.cz

Key words: keratinocyte, cancer stem cell, tumor stroma, keratin 8, keratin 19 , vimentin

\section{Introduction}

The volume of data indicating a role of genetically altered adult tissue stem cells in cancer formation (including basal and squamous cell carcinoma) is rapidly increasing (1-8). According to our previous studies, very poorly differentiated malignant keratinocytes are present, with some phenotypical markers of epidermal stem cells on the periphery of the squamous cell carcinoma node/nodule where the cells with features of differentiated elements are located in the centre of the tumor $(9,10)$. The majority of epithelial cancer cell lines, which are those that can form tumors after grafting to immunosuppressed mice, exhibit markers of stem cells that gradually disappear during the prolonged cultivation $(11,12)$. Normal embryonic stem cells introduced to the adult organism are highly tumorigenic as observed for more than 30 years (13). Since these malignant cells are able to form normal tissue in mice after their introduction to mouse blastocysts, it can be concluded that these cells are genetically normal and their malignant conversion is influenced by the specific microenvironment of adult tissue that is nonphysiological for embryonic cells. It is widely accepted that the maintenance of stemness in adult tissue stem cells is controlled by the specific microenvironment, known as the niche $(14,15)$. Although the stem cell niche in some adult stem cells, such as the epidermal ones has been quite well characterized at the molecular level (16), niche modeling in tissue culture conditions and a prolonged expansion of stem cells has not been successful thus far.

When we accept the hypothesis on the existence of cancer stem cells (as mentioned above), the special microenvironment or niche for propagation of the cancer stem will also be necessary for their function and it can be provided by the cells of cancer stroma (17). The impact of stromal cells on the tumor elements was observed predominantly in breast $(18)$, prostate gland $(19,20)$ and colon cancer $(21)$. The fibroblasts isolated from basal or squamous cell carcinoma are able to influence significantly the phenotype of cocultured normal interfollicular keratinocytes to be similar to the phenotype of malignant epithelial tumor cells from which the 
stromal cells were prepared $(22,23)$. Although the molecular mechanism of the stromal cell action to cancer cells is not clear, the role of specific growth factors/cytokines can be expected because the direct contact between stromal and epithelial cells is not necessary $(22,23)$.

The nature of tumor-associated fibroblasts is not clear as yet, but in principle they can arise from three different mechanisms or their combination: i) the cytokine/growth factors produced by the malignant cells can influence the local fibroblast population that will consequently support the growth of cancer cells (21); ii) the cancer cells can fuse with the local fibroblasts and form polyploid stromal elements (24) and iii) the direct formation of stromal fibroblasts by the epithelial-mesenchymal transition of malignant epithelium to fibroblastoid stromal cells (25).

Epidermal stem cells are located in the bulge region of the outer root sheath of a hair follicle and also in the basal layer of the interfollicular epidermis (26). In this study we cultured the normal human hair follicle and interfollicular keratinocytes with TC- 1 cells. TC- 1 cells were isolated after the co-transfection of mouse (C57/B6) lung epithelial cells with E6 and E7 genes of human papillomavirus type 16 (HPV16) and by an activated $\mathrm{H}$-ras oncogene to maintain their malignant properties (27). These cells were employed as they acquire a fibroblast-like morphology that includes the disappearance of keratins and are highly oncogenic for syngeneic animals. When the stromal cells originate in cancer epithelium, they will carry the same genetic alterations as the epithelial tumor cells. TC-1 cells that were originally epithelial exhibit the properties of fibroblast and they have the same basic genetic alterations as the putative original cancer epithelium where the $E 6$ and $E 7$ genes are present and expressed (28). Therefore, we employed these cells as a model of stromal cells formed from tumor epithelium because they are the fibroblasts containing gene sequences typical for HPV16-transformed squamous epithelial cells from which they originated. The phenotype of the two cell types, i.e. normal hair follicle (NHF) and normal interfollicular epidermal (NIF) keratinocytes, cultured under the influence of TC-1 cells was monitored and compared with the phenotype of the same cells cultured on a mouse 3T3 cell standard feeder (29). These cells are also of mouse origin and are known to support the growth and physiological differentiation pattern in the normal human keratinocytes under in vitro conditions $(22,23)$.

\section{Materials and methods}

Preparation of normal hair follicle and interfollicular keratinocytes. Skin samples were obtained from the Department of Aesthetic Surgery of the Third Faculty of Medicine of the Charles University in Prague according to the criteria of the Helsinki Declaration. Informed consent of patients was obtained and the study was approved by the local ethics committee. Skin samples from the breast of 2 female donors were employed. NHF and NIF keratinocytes were prepared and subcultured as described previously (30).

Cell lines. TC- 1 cells kindly provided by Dr T.C. Wu (Johns Hopkins University, Baltimore) were prepared by the transformation of C57BL/6 primary mouse lung epithelial cells by HPV 16 E6/E7 oncogenes and the activated H-ras oncogene (27). They were maintained as previously described (31). In the present experiments cells from the 3rd passage, derived from a large frozen stock, were used. 3T3 as mouse embryonic fibroblasts (32) were propagated in H-MEM (Hanks' salts modified Eagle's medium, SevaPharma, Prague, Czech Republic) with $10 \%$ bovine serum (ZVOS, Hustopece, Czech Republic) at $37^{\circ} \mathrm{C}$ and $3.3 \% \mathrm{CO}_{2}$.

Coculture of keratinocytes with TC-1 and $3 T 3$ cells. The two types of keratinocytes were cocultured with TC- 1 for 6 or 11 days, respectively. The proliferation activity of the feeder cells was stopped using mitomycin C (Sigma-Aldrich, Prague, Czech Republic) at a concentration of $25 \mu \mathrm{g} / \mathrm{ml}^{-1}$ for $3 \mathrm{~h}$ prior to cocultivation. Feeder cells were seeded on cover glasses at a density of 25,000 cells $/ \mathrm{cm}^{2}$ and cultured for $24 \mathrm{~h}$. Then the suspension of freshly prepared NHF and NIF keratinocytes $\left(20,000\right.$ cells $\left./ \mathrm{cm}^{2}\right)$ was added. They were allowed to adhere for $15 \mathrm{~min}$ on the surface of preseeded cover glasses and all non-adherent cells were washed out. The cells were cultivated in the keratinocyte medium at $37^{\circ} \mathrm{C}$ and $3.3 \% \mathrm{CO}_{2}$ (22). Keratinocytes cocultured with $3 \mathrm{~T} 3$ fibroblasts under the same conditions were used as a control. The growth and size of the quickly adhered keratinocytes were compared with the exposed cells.

To distinguish between the effect of direct contact of the keratinocytes with experimental TC-1 fibroblasts and the role of the medium conditioned by their products, we evaluated the phenotype of keratinocytes separated from the fibroblasts during their coculture by a microporous membrane (Transwell Inserts, Corning, Acton, USA) as described (22).

Immunocytochemistry. The procedure of multiple labeling at a single cell level was employed (33). Cells were briefly fixed with paraformaldehyde, washed in PBS and permeabilized by Triton X-100 (Sigma-Aldrich). All antibodies were diluted as recommended by the supplier. A panel of keratins was visualized using the mouse monoclonal antibody LP34, by anti-high molecular weight keratins (both from Dako, Brno, Czech Republic) and by rabbit polyclonal antibody (Abcam, Cambridge, UK). It should be recalled that keratin type 8 is physiologically not present in squamous cell epithelia, but its expression in the cells of squamous cell carcinoma is a marker of poor clinical prognosis for the respective patient $(34,35)$. Keratin 19 was also detected by the mouse monoclonal antibody (Dako) as it is expressed in epidermal stem cells (36). Vimentin which is normally not present in epithelial cells, can be used in colocalization with keratins as a marker of epithelial-mesenchymal transition (25). This process is important for tumor spreading in organisms (37). Such colocalization was studied in cultured cells using the mouse monoclonal antibody (Dako). Nucleostemin, a protein important for the control of stemness and proliferation, was detected by the goat polyclonal antibody (Neuromics, Bloomington, MN, USA). Although nucleostemin is not an exclusive marker of epidermal stem cells, it is characteristic of a distinct population of keratinocytes cultivated in vitro $(22,23,38)$. The well-known marker of proliferating cells, Ki67, was detected by the mouse monoclonal antibody (Dako). 

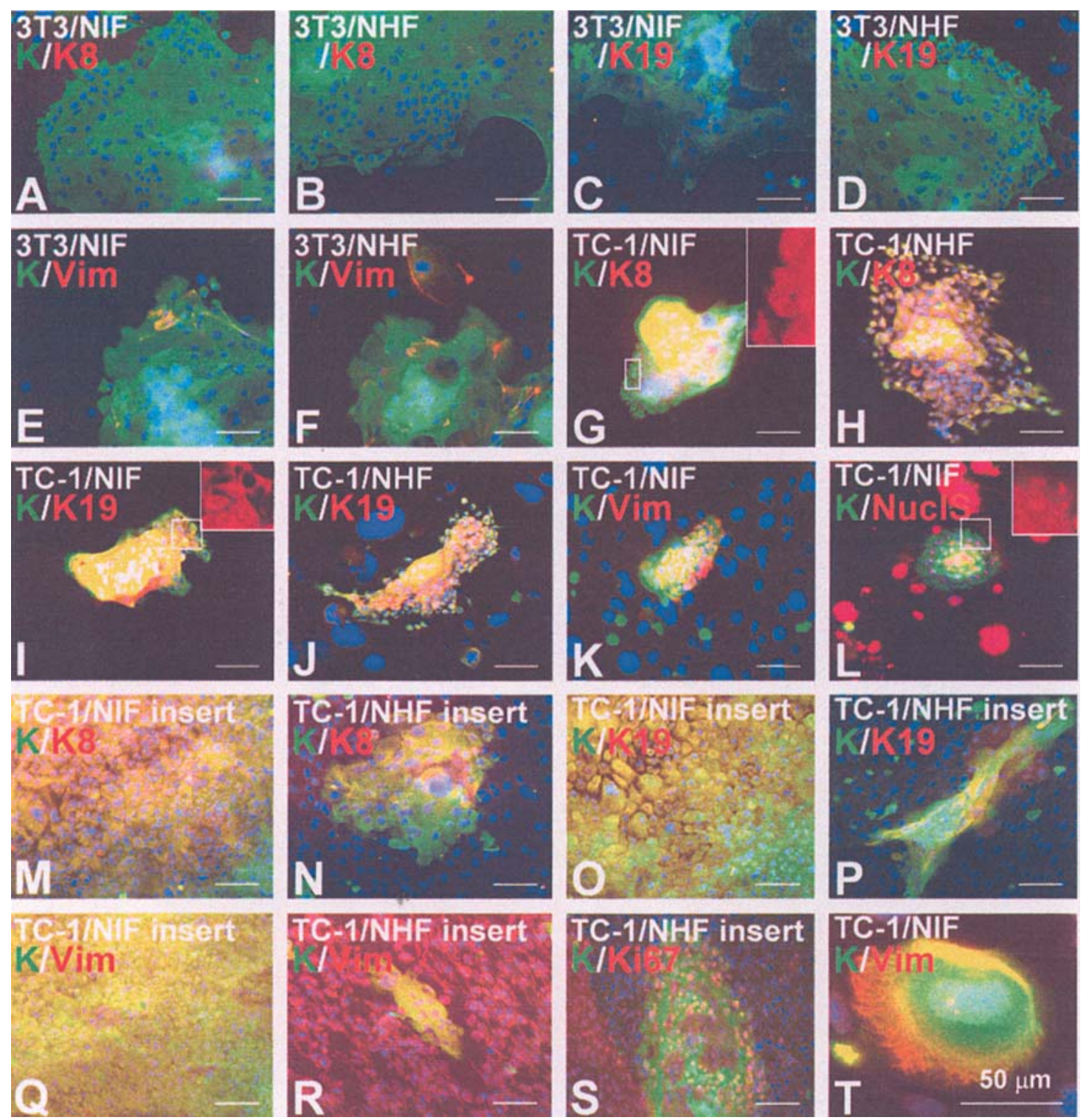

Figure 1. Detection of the panel of keratins (green signal; A-T), of keratin 8 (red signal; A, B, G, H, M and N), of keratin 19 (red signal; C, D, I, J, O and P), of vimentin (red signal; E, F, K, Q, R and T), of nucleostemin (red signal; L) and of Ki67 (red signal; S) in normal interfollicular keratinocytes (NIF; A, C, E, G, I, K, L, M, O, Q and T) and in normal hair follicle keratinocytes (NHF; B, D, F, H, J, N, P, R and S) cultured in the presence of 3 T3 (A-F) and TC-1 cells (G-T), respectively. The inset shows details of K8 (G), K19 (I) and nucleostemin (L) expression in the red canal only. The yellow color indicates the colocalization of signals of similar intensity. The nuclei were stained with DAPI and the scale is $50 \mu \mathrm{m}$.

The specificity of immunohistochemical reaction was tested by omission of the first step antibodies or by their replacement with antibodies against thyreoglobulin which do not normally occur in the studied cells. In the case of monoclonals, an antibody of the same isotype was used as a control. FITClabeled swine anti-mouse immunoglobulins (A1SeVa, Prague, Czech Republic), FITC-labeled swine anti-rabbit immunoglobulins (AlSeVa), TRITC-labeled goat anti-mouse immunoglobulins (Sigma-Aldrich) and TRITC-labeled donkey anti-goat immunoglobulins (Jackson Laboratories, West Grove, PA, USA), respectively, were used as the second step antibody. Nuclear DNA was counterstained with DAPI (4',6'diamidino-2-phenylindole dilactate, Sigma-Aldrich). Specimens were mounted with Vectashield (Vector Laboratories, Burlingame, CA, USA) and examined by fluorescence microscopy using a Nikon Eclipse 90i microscope (Nikon, Prague, Czech Republic) equipped with filterblocks specific for FITC, TRITC and DAPI, respectively, a high resolution CCD camera Cool-1300Q (Vosskühler, Osnabrick, Germany) and a Lucia 5.1 computer-assisted image analysis system (Laboratory Imaging, Prague, Czech Republic). This equipment was also used for measuring the mean area of keratinocyte nuclei. The results were evaluated using Student's unpaired t-test.

\section{Results}

The influence of TC-1 cells on NHF and NIF keratinocyte growth and cell size. The two cell types, i.e. NHF and NIF keratinocytes formed typical flat colonies when they had been cocultured with $3 \mathrm{~T} 3$ feeder cells (Fig. 1A-F). In contrast, NHF and NIF keratinocytes cultured on TC-1 feeder cells formed very small and dome-shaped colonies with papilloma-like morphology (Fig. 1G-L). As expected, the 

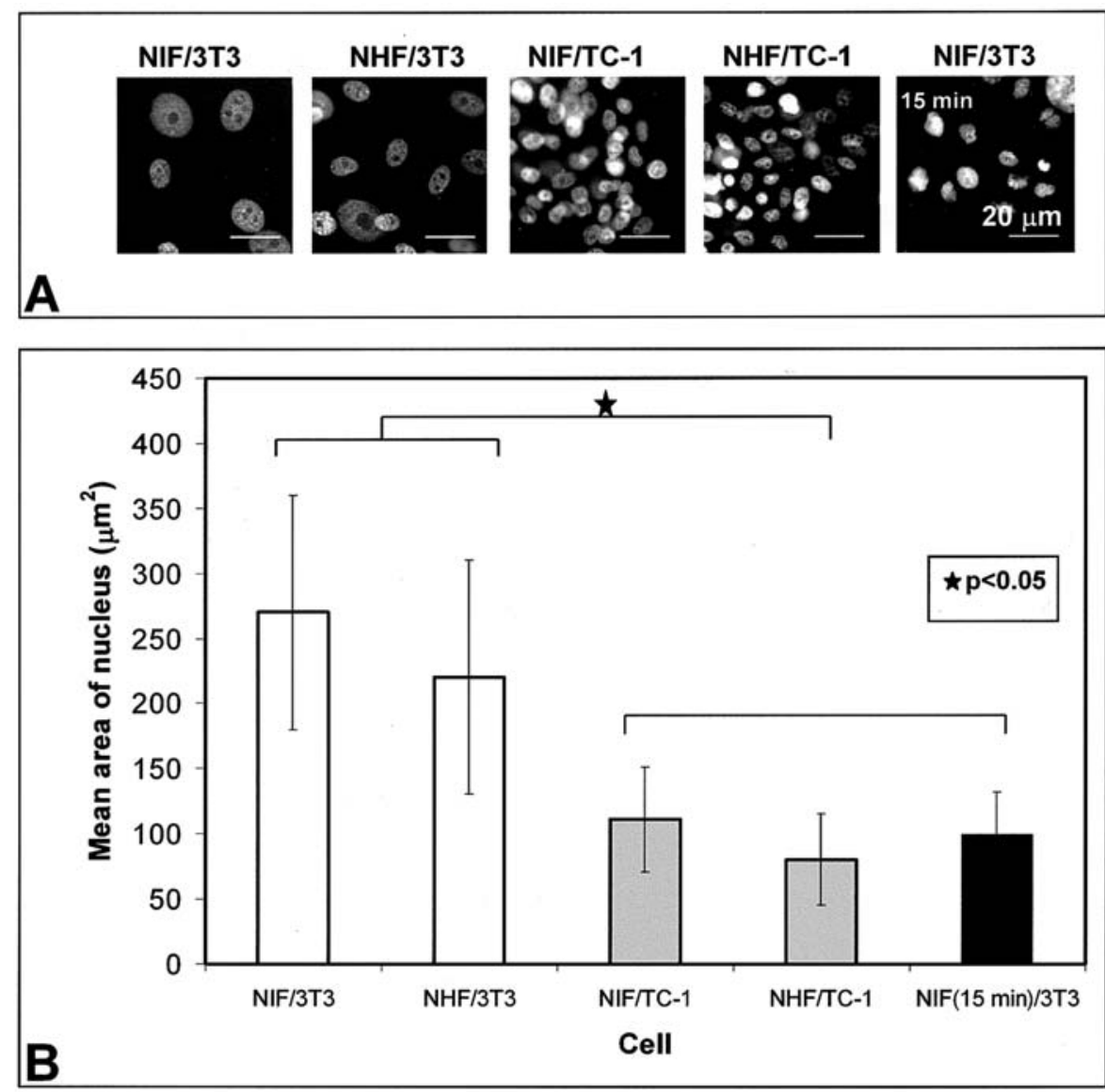

Figure 2. The comparison of size of DAPI-positive nuclei of normal interfollicular (NIF) and normal hair follicle keratinocytes (NHF) cultured in the presence of 3 T3 fibroblasts and TC-1 cells. Interfollicular keratinocytes that adhered only for 15 min are indicated as ' 15 min'. Subsequently, non-attached cells were removed and only those which adhered were cultured (A). The graph (B) compares the mean area of keratinocyte nuclei cultured as described above. The scale is $20 \mu \mathrm{m}$ and the statistical significance was estimated using unpaired Student's t-test at a significance level of $\mathrm{p}<0.05$.

colonies became enlarged during the cultivation period from days 6 to 11 (data not shown). While NIF keratinocytes formed large colonies when they were separated from TC-1 cells by a microporous membrane, only small colonies were observed if NHF keratinocytes were cultured under the same conditions (Fig. 1M-S). A possible role of the mitomycin $\mathrm{C}$ pretreatment of $\mathrm{TC}-1$ in direct coculture experiments on keratinocyte growth was tested in an experiment in which the two cell populations were separated by a microporous membrane. No significant differences were observed, indicating a negligible influence of this procedure on the behavior of keratinocytes. Notably, NHF and NIF keratinocytes cultured in the presence of TC-1 were very small (Figs. 1 and 2). Since the cell borders were not distinguishable in all cells, we measured the areas of DAPI-positive nuclei. This reactivity reflects the size of the cells (Fig. 2). When the keratinocytes cocultured with TC-1 cells and the rapidly adhering NIF keratinocytes were compared, the nuclear areas were quite similar (Fig. 2).

Effects of TC-1 on NHF and NIF keratinocyte phenotype. In comparison with cultures in which $3 \mathrm{~T} 3$ feeder cells were used, we observed an increased number of dead cells with an unspecific positive signal for the studied markers and with no signal for the DAPI staining of DNA when the TC- 1 feeder was employed. The phenotype of NHF and NIF keratinocytes
Table I. Phenotype of keratinocytes cultured under the influence of $3 \mathrm{~T} 3$ and TC-1 as a direct coculture.

\begin{tabular}{lccccc}
\hline & \multicolumn{2}{c}{3 3T3 } & & \multicolumn{2}{c}{ TC-1 } \\
\cline { 2 - 3 } \cline { 5 - 6 } Marker & NHF & NIF & & NHF & NIF \\
\hline K & ++ & ++ & ++ & ++ \\
K8 & - & - & ++ & ++ \\
K19 & - & - & ++ & ++ \\
VIM & - & - & ++ & ++ \\
NuclS & + & - & ++ & ++ \\
Ki67 & + & + & + & + \\
\hline
\end{tabular}

-, no positive cells;,$+ 25-50 \%$ of positive cells and,$++>50 \%$ of positive cells.

cultured in the presence of TC-1 cells was greatly different from those maintained in the presence of 3T3 cells (Table I and Fig. 1A-F). In principle, no qualitative differences between the sensitivity of NHF and NIF to TC-1 were found concerning the studied phenotype (Fig. 1G-J). Nearly all keratinocytes in the presence of TC- 1 exhibited a signal for the keratins 8 and 19 (Fig. 1G-J) and for vimentin (Fig. 1K). They contained 
nucleostemin-positive nucleoli (Fig. 1L) that were also present in the nuclei of NHF cultured under the influence of $3 \mathrm{~T} 3$, but not in the nuclei of NIF cocultured with $3 \mathrm{~T} 3$ fibroblasts. A marked portion of keratinocytes was actively proliferating as estimated by the expression of $\mathrm{Ki} 67$ in the two types of keratinocytes cultured with $3 \mathrm{~T} 3$ and TC-1 (data not shown).

The separation of cell populations (i.e. TC- 1 fibroblasts and keratinocytes) by a microporous membrane had no effect on the high expression of the two studied keratin types (8 and 19), vimentin and Ki67 (Fig. 1M-S).

A small proportion of cells $(<5 \%)$ in the coculture of TC-1 and keratinocytes was large $(>100 \mu \mathrm{m}$ in diameter) with the large nuclei exhibiting keratins and vimentin (Fig. 1T).

\section{Discussion}

This study demonstrated the influence of $\mathrm{TC}-1$ cells (HPV16-transformed mouse lung epithelial cells acquiring the fibroblast properties) on two types of keratinocytes (NHF and NIF). At variance with the control 3T3 cells, TC-1 cells induced a formation of highly abnormal papilloma-like colonies. The size of NHF and NIF cells was significantly reduced under the TC-1 cell influence. It remained similar to the size of quickly adhering keratinocytes. This observation appears to be important, as stem cells, including epidermal ones are known to be very small (39-42).

Concerning the phenotype of normal human hair follicle and interfollicular keratinocytes, TC-1 cells but not the control 3T3 cells induced a high level expression of keratins 8 and 19, vimentin and nucleostemin. These phenotype changes indicated the important effect of TC-1 on the differentiation of normal keratinocytes, because keratin 19 has not been observed in postnatal interfollicular epidermis $(36,43)$. Its presence in keratinocytes of the bulge region of the hair follicle appears to be restricted to the stem epidermal stem cell (36). Under pathological conditions this has been observed in some basal cell carcinomas (40). Keratin 8 which is induced by TC- 1 is not expressed by the cells of squamous epithelia in the postnatal period under physiological conditions but its expression in the squamous cell carcinoma has been recognized as a marker of poor clinical prognosis of patients (44). The two keratins are not expressed in human keratinocytes during the prolonged cultivation in vitro except for the keratinocytes cocultured with stromal cells from basal or squamous cell carcinomas exhibiting the presence of keratins 8 or $19(22,23)$. The coexpression of keratins and vimentin in keratinocytes cocultured with TC-1 cells can be interpreted as evidence of epithelial-mesenchymal transition $(25,45)$ of the normal keratinocytes. However, additional evidence substantiating this conclusion are needed. This phenomenon can be important for the spreading of the tumor in the organism (25). The results described above were observed even if the two cell populations had been separated by a microporous membrane, thereby indicating the involvement of some soluble bioactive factors produced by TC- 1 cells.

These results are in agreement with the concepts which assume that the mesenchymal cells play a leading role in the control of the development of epidermis including appendages such as hair or teeth $(46,47)$. Even postnatally, fibroblasts significantly influence the expression of specific keratins in epidermal cells (48). The strong influence of TC- 1 cells on normal keratinocytes, as demonstrated in the present experiments, is compatible with the concept that tumor stroma play a fundamental role in the biology of cancer arising from squamous epithelia. The presented results indicate that fibroblastoid cells formed by mesenchymal transition from cancer epithelium can strongly influence the properties of epithelial cells by paracrine fashion. Since the present data were obtained using human keratinocytes and mousetransformed fibroblastoid cells, the putative factors involved in the events reported are not species-specific.

In conclusion, the model described in this study can help us to understand the biology of squamous cell carcinomas induced by HPV infection, such as some head and neck cancers and all or nearly all carcinomas of the uterine cervix $(28,49)$. The fibroblastoid but originally epithelial cells expressing the E6/E7 proteins were highly active as is demonstrated by their influence on keratinocyte differentiation and epithelial-mesenchymal transition, a phenomenon supporting tumor growth and spreading in the organism.

\section{Acknowledgements}

This study was supported by the Ministry of Education Youth and Sport of the Czech Republic, project No. MSM0021620806 and 1M0021620803 as well as by the Internal Grant Agency of the Ministry of Health, project No. NR 9049-3 and NR9075-3. The authors would like to thank Eva Vancová, Iva Burdová and Vít Hajdúch for their technical assistance.

\section{References}

1. Reya T, Morrison SJ, Clarke MF and Weissman IL: Stem cells, cancer, and cancer stem cells. Nature 414: 105-111, 2001.

2. Sell S: Stem cell origin of cancer and differentiation therapy. Crit Rev Oncol Hematol 51: 1-28, 2004

3. Morris RJ: A perspective on keratinocyte stem cells as targets for skin carcinogenesis. Differentiation 72: 381-386, 2004.

4. Burkert J, Wright NA and Alison MR: Stem cells and cancer: an intimate relationship. J Pathol 209: 287-297, 2006.

5. Costea DE, Tsinkalovsky O, Vintermyr OK, Johannessen AC and Mackenzie IC: Cancer stem cells - new and potentially important targets for the therapy of oral squamous cell carcinoma. Oral Dis 12: 443-454, 2006.

6. Finlan LE and Hupp TR: Epidermal stem cells and cancer stem cells: insights into cancer and potential therapeutic strategies. Eur J Cancer 42: 1283-1292, 2006.

7. Janes SM and Watt FM: New roles for integrins in squamous cell carcinoma. Nature Rev Cancer 6: 175-183, 2006.

8. Motlík J, Klíma J, Dvoránková B and Smetana K Jr: Porcine epidermal stem cells as a biomedical model for wound healing and normal/malignant epithelial cell propagation. Theriogenology 67: 105-111, 2007.

9. Plzák J, Betka J, Smetana K Jr, Chovanec M, Kaltner H, André S, Kodet R and Gabius H-J: Galectin-3: an emerging prognostic indicator in advanced head and neck carcinoma. Eur J Cancer 40: 2324-2330, 2004.

10. Chovanec M, Smetana K Jr, Betka J, Plzák J, Brabec J, Moya-Álvarez V, André S, Kodet R and Gabius H-J: Correlation of expression of nuclear proteins pKi67 and p63 with lectin histochemical features in head and neck squamous cell cancer. Int J Oncol 27: 409-415, 2005.

11. Mackenzie IC: Stem cell properties and epithelial malignancies. Eur J Cancer 42: 1204-1212, 2006.

12. Smetana K Jr, Dvoránková B Chovanec M, Boucek J, Klíma J, Motlík J, Lensch M, Kaltner H, André S and Gabius H-J: Nuclear presence of adhesion-/growth-regulatory galectins in normal/ malignant cells of squamous epithelial origin. Histochem Cell Biol 125: 171-182, 2006. 
13. Mintz B and Illmensee K: Normal genetically mosaic mice produced from malignant teratocarcinoma cells. Proc Natl Acad Sci USA 72: 3585-3589, 1975.

14. Watt FM and Hogan BL: Out of Eden: stem cells and their niches. Science 287: 1427-1430, 2000.

15. Li Z and Li L: Understanding hematopoietic stem-cell microenvironments. Trends Biochem Sci 31: 589-595, 2006.

16. Fuchs E, Tumbar T and Guasch G: Socializing with the neighbors: review stem cells and their niche. Cell 116: 769-778, 2004.

17. Li L and Neaves WB: Normal stem cells and cancer stem cells: the niche matters. Cancer Res 66: 4554-4557, 2006.

18. Bissell MJ and LaBarge MA: Context, tissue plasticity, and cancer: Are tumor stem cells also regulated by the microenvironment? Cancer Cell 7: 17-23, 2005.

19. Cunha GR, Hayward SW, Wang YZ and Rickey WA: Role of the stroma microenvironment in carcinogenesis of the prostate. Int J Cancer 107: 1-10, 2003.

20. Condon MS: The role of the stromal microenvironment in prostate cancer. Semin Cancer Biol 15: 132-137, 2005.

21. Nakagawa H, Liyanarchchi S, Davuluri RD, Auer H, Martin EW Jr, de la Chapelle A and Frankel WL: Role of cancer-associated stroma fibroblasts in metastatic colon cancer to the liver and their expression profiles. Oncogene 23: 7366-7377, 2004.

22. Lacina L, Smetana K Jr, Dvoránková B, Pytlík R, Kideryová L, Kucerová L, Plzáková Z, Stork J, Gabius H-J and André S: Stromal fibroblasts from basal cell carcinoma affect phenotype of normal keratinocytes. Br J Dermatol 156: 819-829, 2007.

23. Lacina L, Dvoránkova B, Smetana K Jr, Chovanec M, Plzák J, Tachezy R, Kideryová L, Kucerová L, Cada Z, Boucek J, Kodet R, André S and Gabius H-J: Marker profiling of normal keratinocytes identifies the stroma from squamous cell carcinoma of the oral cavity as a modulatory microenvironment in co-culture. Int Radiation Biol 83: 837-848, 2007.

24. Jacobsen BM, Chuck Harrell JC, Jedlicka P, Borgis VF, Varella-Garcia M and Horwitz KB: Spontaneous fusion with, and transformation of mouse stroma by, malignant human breast cancer epithelium. Cancer Res 66: 8274-8279, 2006.

25. Petersen OW, Nielsen HL, Gudjonsson T, Villadsen R, Rank F, Niebuhr E, Bissell MJ and Rønnov-Jessen L: Epithelial to mesenchymal transition in human breast cancer can provide a nonmalignant stroma. Am J Pathol 162: 391-402, 2003.

26. Watt FM, Celso CL and Silva-Vargas V: Epidermal stem cells: an update. Current Opinion Genet Develop 16: 518-524, 2006

27. Lin K-Y, Guarnieri FG, Staveley-O'Carroll KF, Levitsky HI, August JT, Pardoll DM and Wu TC: Treatment of established tumors with a novel vaccine that enhances major histocompatibility class II presentation of tumor antigen. Cancer Res 56: 21-26, 1996.

28. Doorbar J: Molecular biology of human papilloma virus infection and cervical cancer. Clin Sci 110: 524-541, 2006.

29. Rheinwald JG and Green H: Serial cultivation of strains of human epidermal keratinocytes: the formation of keratinizing colonies from single cells. Cell 6: 331-343, 1975.

30. Purkrábková T, Smetana K Jr, Dvoránková B, Holíková Z, Böck C, Lensch M, André S, Pytlík R, Liu F-T, Klíma J Smetana K, Motlík J and Gabius H-J: New aspects of galectin functionality in nuclei of cultured bone marrow stromal and epidermal cells: biotinylated galectins as tool to detect specific binding sites. Biol Cell 95: 535-545, 2003.

31. Smahel M, Síma P, Ludvíková V, Marinov I, Pokorná D and Vonka V: Immunisation with modified HPV16 E7 genes against mouse oncogenic TC-1 cell sublines with downregulated expression of MHC class I molecules. Vaccine 21: 1125-1136, 2003.

32. Todaro GJ and Green H: Quantitative studies of the growth mouse embryo cells in culture and their development into established lines. J Cell Biol 17: 299-313, 1963.
33. Fronková V, Holíková Z, Liu F-T, Homolka J, Rijken DC, André S, Bovin NV, Smetana K Jr and Gabius H-J: Simultaneous detection of endogenous lectins and their binding capability at the single cell-level-a technical note. Folia Biol 45: 157-162, 1999.

34. Carrilho C, Alberto M, Buane L and David L: Keratins 8, 10, 13, and 17 are useful markers in the diagnosis of human cervix carcinomas. Hum Pathol 35: 546-551, 2004.

35. Fillies T, Werkmeister R, Packeisen J, Brandt B, Morin P, Weingart D, Joos U and Berger H: Cytokeratin 8/18 expression indicates a poor prognosis in squamous cell carcinomas of the oral cavity. BMC Cancer 6: 10-18, 2006.

36. Michel M, Török N, Godbout M-J, Lussier M, Gaudreau P, Royal A and Germain L: Keratin 19 as a biochemical marker of skin stem cells in vivo and in vitro: keratin 19 expressing cells are differentially located in function of anatomic sites, and their number varies with donor age and culture stage. J Cell Sci 109: 1017-1028, 1996.

37. Thiery JP and Sleeman JP: Complex networks orchestrace epithelial-mesenchymal transitions. Nature Rev Mol Cell Biol 7: 131-142, 2006.

38. Lacina L, Smetana K Jr, Dvoránková B, Stork J, Plzáková Z and Gabius H-J: Immunocyto- and histochemical profiling of nucleostemin expression: marker of epidermal stem cells? J Dermatol Sci 44: 73-80, 2006.

39. Barrandon J and Green H: Cell size as a determinant of the clone-forming ability of human keratinocytes. Proc Natl Acad Sci USA 82: 5390-5394, 1985

40. Dvoránková B, Smetana K Jr, Chovanec M, Lacina L, Stork J, Plzáková Z, Galovicová M and Gabius H-J: Transient expression of keratin K19 is induced in originally negative interfollicular epidermal cells by adhesion of suspended cells. Int J Mol Med 16: 525-531, 2005.

41. Kucia M, Reca R, Campbell FR, Zuba-Surma R, Majka M, Ratajczak J and Ratajczak MZ: A population of very small embryonic-like (VSEL) CXCR4+ SSEA-1+ OCT-4+ stem cells identified in adult bone marrow. Leukemia 20: 857-869, 2006.

42. Klíma J, Motlík J, Gabius H-J and Smetana K Jr: Phenotypic characterization of porcine interfollicular keratinocytes separated by elutriation: a technical note. Folia Biol 53: 33-36, 2007.

43. Commo S, Gaillard O and Bernard BA: The human hair follicle contains two distinct K19 positive compartments in outer root sheath: a unifying hypothesis for stem cell reservoir? Differentiation 66: 157-164, 2000.

44. Gires O, Münz M, Schaffrik M, Kleu C, Rauch J, Ahlemann M, Eberle D, Mack B, Wolleneberg B, Lang S, Hofmann T, Hammerschmidt W and Zeidler R: Profile identification of disease-associated humoral antigens using AMIDA, a novel proteomics-based technology. Cell Mol Life Sci 61: 1198-1207, 2004.

45. Kong W, Li S, Liu C, Bari AS, Longaker M and Lorenz HP: Epithelial-mesenchymal transition occurs after epidermal development in mouse skin. Exp Cell Res 312: 3959-3968, 2006.

46. Peterková R, Peterka M, Viriot L and Lesot R: Dentition development and budding morphogenesis. J Craniofac Genet Dev Biol 20: 158-172, 2000

47. Millaire SE: Molecular mechanisms regulating hair follicle development. J Invest Dermatol 118: 216-225, 2002.

48. Yamaguchi Y, Itami S, Tarutani M, Hosokawa K, Miura H and Yoshikawa K: Regulation of keratin 9 in nonpalmoplantar keratinocytes by palmoplantar fibroblasts through epithelialmesenchymal interactions. J Invest Dermatol 112: 483-488, 1999.

49. Kreimer AR, Clifford GM, Boyle P and Franceschi S: Human papilloma virus types in head and neck squamous cell carcinomas worldwide: a systematic review. Cancer Epidemiol Biomarkers Prev 14: 467-475, 2005. 